\section{Gastritis, Aspirin, and Alcohol}

SIR,-I was interested in Dr. D. N. Croft's excellent article on gastritis (21 October, p. 164), and welcome the prominence that he gives to the role of aspirin and alcohol in provoking gastritis and haematemesis. $\mathrm{He}$ shows that gastritis is usually self-induced. $\mathrm{He}$ does not, however, mention the considerable risk of gastroduodenal haemorrhage when alcohol and aspirin are taken together, the latter often at the end of a binge in an endeavour to prevent a hangover.

Some years ago I reported to the Association of Physicians of Region No. 1 the results of a small survey of every emergency medical admission with haematemesis and melaena to this hospital in 1958 and in 1960 (unpublished). In 108 cases we found that 72 had taken aspirin in some form, as far as could be ascertained, within 24 hours of the onset of bleeding. In the year 1958, of 31 male admissions 23 had taken aspirin and 16 had taken alcohol within 24 hours of the onset, and 10 had taken both. We thought that alcohol considerably increased the risk of bleeding due to aspirin, and it was significant that male admissions with haematemesis were more frequent at week-ends and during public holidays.

Incidentally, we found that at first patients often denied aspirin ingestion, until they were carefully interrogated using several of the more popular trade names. We now hand each patient a printed list of the 321 aspirincontaining preparations they would do well to avoid in future. The most confusing was undoubtedly Alka-seltzer, none of its victims being aware of the aspirin content of this well-advertised preparation, and many thinking that it was purely an alkali and therefore taking it for gastric discomfort or pain.

Further inquiry was made into the drinking habits of the ulcer patients. There were 75 males with gastroduodenal bleeding, and 48 of these were considerable drinkers, nearly always bitter beer, and consumption varied from a mere one gallon (4.5 1.) of beer per week to as much as seven gallons per week. Of these 48 individuals 32 were considered to have a duodenal ulcer, mostly confirmed or strongly suspected. These and other figures lead one to reflect that in this district regular beer drinking, especially bitter beer, over a long number of years eventually leads to duodenal ulcer, and one speculates about whether this may explain why it is that duodenal ulcer is so much more common in men than women. If this is correct the incidence of duodenal ulcer in total abstainers should be low. It seems to me that the role of alcohol in relation to gastroduodenal troubles has hitherto been underrated, and that here is a problem which merits wider attention and further study. Also the public should be warned not to take aspirin after drinking.-I am, etc.,

North Ormesby Hospital.

C. E. Astley.

Middlesbrough.

\section{Body Building on Drugs}

SIR,-Your leading article on the use of anabolic steroids in athletic training (11 November, p. 310) in reply to Dr. D. E. Pearsons's letter (11 November, p. 353) is both timely and of importance. It may, however, be of interest to you to know that this subject has already been considered at some length by the Medical Advisory Committee to the British Olympic Association, and that they utterly condemned the use of anabolic steroids in athletic training and pointed out the possible dangers involved in taking them. A copy of this recommendation has been sent to all the governing bodies of sport in this country.

In addition to this the International Olympic Committee has issued the following statement to the National Olympic Committees of 123 countries: "The International Olympic Committee considers the use of anabolic steroids (except for medical purposes) constitutes 'doping' from the Olympic viewpoint."-I am, etc.,

\section{West Haddon, $\quad \begin{gathered}\text { Honorary Medical OOfficer, } \\ \text { British Olympic Association }\end{gathered}$ \\ Near Rugby.}

\section{Coagulation of Rubber Latex in the Stomach}

SIR,-The common poisons used by agricultural workers in Ceylon attempting suicide are insecticides, which are easily available to them. Rubber latex is not considered to be a poisonous substance, and we report here a case of attempted suicide by ingestion of rubber latex. The only symptoms produced by the ingestion of rubber latex were due to the mechanical effects on the stomach of the coagulated rubber latex. ${ }^{2}$ This is an unusual foreign body in the stomach about which there have been no earlier reports in the literature.

A 49-year-old woman who works as a rubber tapper on a rubber estate was admitted to the medical ward with a history of having swallowed a cup full of fresh rubber latex. She had confessed to her daughter that she had taken the rubber latex with the intention of killing herself. She had ingested the rubber latex four hours prior to her admission to hospital. Although alert and conscious at the time she was brough to the hospital outpatients department she refused to answer any questions. Apart from slight abdominal pain, she had no other symptoms, and seemed reasonably comfortable. On examination the pulse was 90 a minute, regular, and blood pressure was $110 / 90 \mathrm{~mm}$. Hg. An elongated sausage-shaped lump was palpated in the epigastrium. It was firm, but could be pitted on pressure. A plain $x$-ray of the abdomen did not reveal any abnormality.

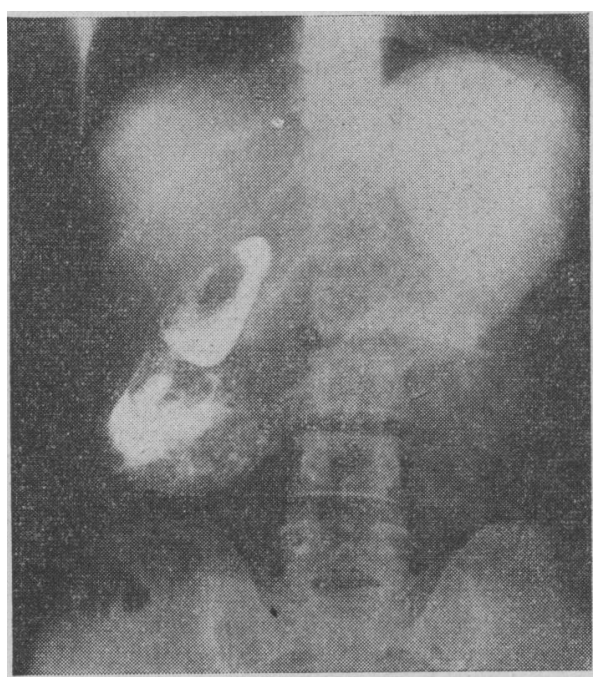

FIG. 1.-X-ray of the abdomen taken after barium showing the filling defects in the stomach and in the second part of the duodenum.
The $x$-ray of the abdomen taken after giving a dilute solution of barium to swallow showed two filling defects; one corresponding with the lump felt in the abdomen in the stomach and the other due to the presence of solid latex in the second part of the duodenum (Fig. 1).

At operation the solid latex, moulded to the shape of the stomach, was removed and the gastrostomy wound closed. This solid rubber was of creamy yellow colour with the impressions of the rugae of the stomach on it (Fig. 2).

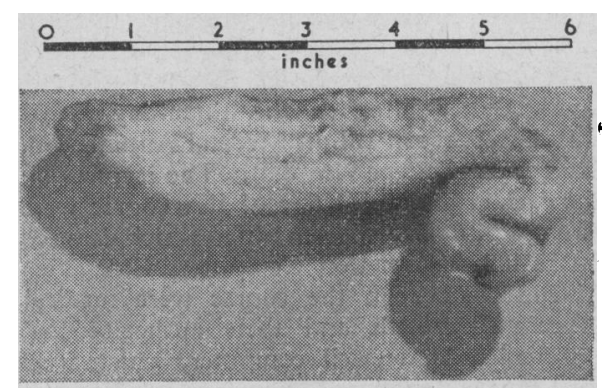

FIG. 2.-The specimen of solid rubber removed from the stomach.

When thrown on the floor it bounced like any other piece of rubber. The other latex lump was identified in the second part of the duodenum. Duodenostomy was done and the lump removed. She made an uneventful recovery. She was later seen by the psychiatrist.

Rubber latex is a milky fluid obtained by cutting the bark of the rubber tree. This latex, when coagulated, forms the solid rubber. In the rubber factories of Ceylon coagulation of rubber is obtained by adding certain chemical substances to the latex. Eight ounces $(200 \mathrm{ml}$.) of $8 \%$ sodium bisulphite and $5 \mathrm{oz} .(125 \mathrm{ml}$ ) of $6 \%$ formic acid are used for 40 gallons $(182$ l.) of latex for it to coagulate. In this particular case the acid present in the stomach must have in some way contributed to the coagulation of the latex in the stomach.

We would like to thank Mr. M. de S. Jayasinghe, of the Photographic Department, General Hospital, Colombo, for his help with the photographs in this case.

-We are, etc.,

\section{K. Thirunavukrarasu.}

K. YOHESWARAN. General Hospital,
Ratnapura, Ceylon.

REFERENCES

Aird, I., A Companion in Surgical Studies, 1958 2nd ed. Edinburgh.

Souttar, H., Textbook of British Surgery, 1956 London

\section{Prevention of Rh-haemolytic Disease}

SIR,-My colleagues and I were interested in Dr. Sheilagh Murray's letter (4 November, p. 296), and the following are the replies to her queries:

The treated and control women in the Liverpool group who had subsequently $\mathrm{Rh}$-positive babies were tested for antibodies immediately after delivery of the second baby. The babies were in all cases Coombs-negative, normal, and liveborn. In the clinical trials elsewhere, al we know is that the babies were also Rh-positive, normal, and liveborn, and that no treated women have made antibody, but we do not know the precise time at which the tests were carried out

As far as we know, the 110 women remaining in the treated group have not become pregnant 